\title{
Epidemiology of indications
}

The recent editorial by Frankel on the epidemiology of indications ${ }^{1}$ is an excellent review of the problem of the interface between research and practice, and the impact of governmental policy decisions on the provision of health care.

Frankel is correct in defining the confusion that exists between health care and health needs. $\mathrm{He}$ is also correct in outlining the deficiencies that exist in our ability to influence decisions on priorities, purchasing, etc. His sensitive analysis of the role of the population in defining what needs to be done, or what can be done, is good. However, his analysis of the issues has omitted examination of the past and is deficient in the blame that he attaches to various groups.

A striking omission of the current NHS reforms has been lack of consultation with expert groups. Many of the changes that were introduced through green and white papers and other documents were promulgated following inadequate consultation between those with knowledge of health services and health services research findings and those concerned with health policy formulation at department level. To some extent our own professional group shares this blamethe Department of Health work on epidemiologically based needs assessment was commissioned by the management executive and undertaken by a variety of groups. It is amazing that those involved in this work neglected Department of Health commissioned research from 10 or more years previously.

Many researchers are critical of those concerned with the commissioning of research and the determination of research priorities. The wisdom of the Department of Health's strategy for health services research in the 1960s has been brought into question by the current and continuing concern with needs assessment today.

McLachlan ${ }^{2}$ has described the establishment of Department of Health's major capability for health services research. This was largely the work of Sir George Godber (the then CMO), Dr Richard Cohen (Deputy Chief Medical Officer), Dr J M G Wilson, Mr J B Cornish, and Mr W Rudoe. This volume details the development of the programme, its initial priorities and the reasons behind them. It also gives some idea of the scope and quantity of work being undertaken at that time.

The first concerted attempt at research commissioning in the late $1960 \mathrm{~s}$ by the Department of Health was the measurement of need for and evaluation of health services. Matthew ${ }^{2}$ points out (pp 27-46) that

"in the last few years the NHS has been increasingly challenged to base its planning on scientific information and analysis, rather than on arguments from theory and established practice. An important long term aim of the Department's research programme is to develop methods for obtaining such information and to establish the limits of what is practicable and economic in provision. Formidable difficulties arise in much of this work and its practical importance is sometimes disputed. This is illustrated by the two subjects that will now be discussed: the measurement of the need for medical care in the community and the evaluation of new ways of providing health services. Some people believe that these subjects present insuperable research difficulties or that the findings would never be used in practice, others that they are of crucial importance to the health service and that it would be very wrong not to arrange major programmes centred on them".

I do not intend to cover the ground that has been cogently outlined by Matthew, which considers the same issues that Frankel deals with in his editorial, and to which both he and others have failed to give credit. However, I do wish to make a number of points.

Frankel chides epidemiologists for neglecting various common conditions but is apparently unaware of the studies on hernia, varicose veins, haemorrhoids, and bunions which were undertaken by Logan and his group in Mersey, and Wedell, Cochrane and others in South Wales. Studies on disability, cardiorespiratory disease, peptic ulceration, and skin disease were undertaken in Lambeth, and on stroke and mental illness in Frimley. In addition, a number of evaluations of new hospitals and changes in service provision, for example short stay versus normal stay, were commissioned and carried out in Frimley and Bury St Edmunds.

It is correct that many of the studies met with difficulties and none satisfied all the criteria which Frankel so rightly expresses. $\mathrm{He}$ is, however, unjust in the apportionment of blame as well as in his suggestion of the lack of adequate data. Blame should be attached, firstly, to those involved in Project 26 who seemed unaware that the Department of Health itself had commissioned and received a large amount of information and research on the determination of health care needs, as well as on the evaluation of the effectiveness of some of the services.

Secondly, those concerned with the administration and commissioning of research also deserve some blame. Their initial insight and courage in commissioning a number of studies which so correctly forecast the present concerns were not followed. In fact, policy decisions were taken counter to the research findings for unexplained reasons. ${ }^{3}$ Researchers certainly indicated where future activities should be concentrated and suggested the areas of possible research and evaluation required. Unfortunately, the support to do this work was never forthcoming.

It is great pity that a new generation of academics and practitioners neglects work undertaken by its predecessors. In view of the demand placed on our skills, thorough examination of previous publications is essential so that we do not continuously reinvent wheels. This 
sorry state of affairs once again demonstrates the need for proper research management. Such need has been expressed in the past ${ }^{4}$ but adequate and achieved.

WALTER HOLLAND

Professor of Public Health Medicine UMDS-St Thomas's Campus, London SE1 integrated management of research is yet to be

1 Frankel S. The epidemiology of indications. Editorial. $f$ Epidemiol Community Health 1991; 45: 257-9.

$2 \mathrm{McL}$ achlan G. Portfolio for health: the role and programme of the DHSS in health services research. London: Nuffield Provincial Hopitals Trust and the Oxford University Press, 1971

3 Morrell DC. Role of research in development of organisation and structure of general practice. BMF 1991; 302: 1313-6.

4 Ashley-Miller M, Kay AW. Initiating and supporting public health research-United Kingdom. In: Holland W, Knox $\mathrm{G}$, Detels R, eds The Oxford textbook of public health (1st edn). Oxford: Oxford University 1985. pp. 402-8.

writings and as an editor by such luminaries as Ryle, Doll, Carstairs, Cochrane, McKeown, Morris, Rutter, Holland, Knox et al) I have some glimmerings of deja vus; and indeed cannot help wondering whether too much valuable skill and effort is going into the rediscovery of known "indications".

I am already on record in What price quality ${ }^{2}$ for my belief in the opportunities for influencing management now open to the practitioners of public health medicine. It seems to me that success in these will depend on the scientific validity of the "indications" provided by epidemiology; but history seems to show that, regrettably, there is a failure to recognise many of the signs of epidemiological practice, as well as its essential complement, the link between knowledge and application.

GORDON MCLACHLAN (Secretary, Nuffield Provincial Hospitals Trust 1955-1986) sponsored and the findings published has gone unheeded. The current obsession with the "reforms" obscures a wealth of "indications" of how to improve the public health.

It is not my intention to comment in detail on Dr Frankel's observations even if (schooled by the
Substantial changes have been registered in death certification rates from asthma over the last few decades, and appreciable rises have been observed in most recent years in several developed countries, including New Zealand, England and Wales, and Italy. ${ }^{1-3}$ These changes have been related to the introduction and use of newer pharmacological treatments, and the recent upward trends to serious acute side effects of some specific formulations, or to the delay caused by these drugs in seeking appropriate treatment of acute severe asthma. ${ }^{4-10}$ This would suggest that the upward trends in asthma mortality are not necessarily a consequence of increased incidence and prevalence of the disease, and should not therefore be consistently reflected in other asthma statistics.

To shed further light on the issue, we have considered trends in hospital admissions for asthma between 1976 and 1986 in Lombardy, the most populated Italian region, with approximately nine million inhabitants. Records of hospital admissions for asthma in Lombardy for the period 1976-86 were obtained from the Regional Department of Epidemiology. From these data, and the corresponding estimates of resident population, age specific and age standardised admission rates were derived. Directly standardised rates were based on the European standard population.

Trends in overall age standardised hospital admission rates for asthma between 1976 and 1986 are presented in the figure and contrasted with national mortality rates over the same calendar period. In both sexes, there was no apparent trend in hospital admission rates over the calendar period considered. When age specific rates were considered, however, appreciable rises were observed in childhood (over $40 \%$ in both sexes), while there was no change in young adults (15-44 years), and noticeable declines in middle and older ages (table).

The interpretation of these trends is not simple, particularly with reference to the different patterns in various age groups, but nonetheless recent trends in admission rates for asthma in Lombardy are substantially different from certified mortality on a national level. Over a comparable calendar period, in fact, overall age 